QUADERNS DE FILOSOFIA VOL. II NÚM. 2 (2015): 29-54

ISSN: 234I-I4I 4 eISSN: 234I-3042 DOI: IO.7203/QFIA.2.2.6852

EZEQUiel ZeRBudis

Universidad Nacional del Litoral, Universidad de Buenos Aires \&

CONICET, Argentina

\title{
Descartes on Corporeal Substances
}

Received: 15/7/15. Accepted: 2/10/15

\begin{abstract}
I defend in this paper the following two theses: first, that Descartes was a Pluralist as regards extended substances, that is, that for him the extended world includes a plurality of bodies, including ordinary objects, each of which may be adequately described as a substance; and that for him the notion of substance is a rather slim notion, making no specific requirements as regards individuation or persistence conditions, and determining therefore no strict constraints on the kind of material objects that may count as substances. In short, I will be arguing for a certain view concerning the extension of the phrase 'extended substance' by defending a specific view of what 'substance' means.
\end{abstract}

Keywords: substance, body, Monism, dependence.

\section{Introduction: Aims AND Overview}

$I^{N}$ $\mathrm{N}$ THE PRESENT PAPER I defend two theses relevant to Descartes's views on extended substances. In the first place, I will defend the view that he was a Pluralist as regards extended substances, that is, I will contend that for Descartes the extended world includes a plurality of bodies and, more specifically, that ordinary objects also count as substances for him. In the second place, and as part of my argument in favour of that thesis, I will defend a particular interpretation of the notion of substance, one according to which this is a rather slim notion, making no requirements as regards individuation or specific per- 
sistence conditions, and imposing therefore no restrictions for the kinds of material objects that may count as substances. In short, I will be arguing for a certain view concerning the extension of the phrase 'extended substance' by defending a specific view of what 'substance' means.

\section{How MANY EXTENDED SUBSTANCES?}

There seems to be no general agreement in the literature as to what would count as a corporeal substance for Descartes. One may get a good idea of the extent of the disagreement in this area by considering the widely differing answers that have been given to the question of just how many corporeal substances there are. One can distinguish in the relevant literature at least three different (groups of) answers:

(i) In the first place, we find an answer that we could describe as Nibilist. This is a view according to which it would be incorrect to say there are any number of individual corporeal substances, but that, in this case, there is just corporeal stuff. This isn't a particularly popular view, but one could think that people, such as Woolhouse (1993), that think that 'corporeal substance' is a mass term, endorse such a view. According to proponents of this view, the question 'How many extended substances there are?' is ill formed, as 'extended substance' isn't a count term in the first place - so that, notice, the view implies that it is incorrect to say that there are individual corporeal substances not because the response to that question is that there are zero such substances, but because, more radically, the question makes no sense. For people that defend this kind of view, the so called 'extended world' is just an aggregate of corporeal stuff. ${ }^{1}$

(ii) On the other hand, one could also defend a Monist position, according to which for Descartes there is just one corporeal substance, namely, the whole extended world. This appears to be or, in any case, to have been until recently, the most popular view among Descartes scholars, having been defended

\footnotetext{
${ }^{1}$ Cf. Woolhouse (1993, 23): '[...] Descartes's view that there are not many corporeal substances does not mean that there is only one, but that there is only corporeal substance as such'. In an earlier paper Woolhouse had already presented this Nihilist view, but was rather uncertain whether to prefer it to Monism: '[...] although there are many minds there are not many extended substances. What we might think of as separate corporeal substances - our own bodies and those of others, the trees and animals around us - are not so. They are merely parts of the extended corporeal substance that God created. Whether one should say that 'extended substance' is a count term (as is 'thinking substance') and that there is "one extended substance", or whether one should say it is a mass term and that there is just "extended substance" is uncertain' (1990, 23-4). See also Stuart (1999, 94-5) for an exposition and critical assessment of the view.
} 
by such influential commentators as, among others, Martial Gueroult (1953), Bernard Williams (1978) and John Cottingham (1986). Among more recent commentators, it has also been endorsed by Jorge Secada (2006). ${ }^{2}$

(iii) Finally, we find what we could describe as the Pluralist view, according to which there are many (typically, indefinitely many) corporeal substances. I would like to distinguish two different varieties of this kind of view, as I will be endorsing one of them and rejecting the other. According to the variety I will eventually reject, (a) quantities of matter do, but ordinary objects do not, qualify as substances - this is a position that has been defended recently by authors such as Matthew Stuart (1999); according to an alternative position, on the other hand, (b) both quantities of matter and ordinary objects can be taken as substances - this is the position that I will endorse (and which is also accepted, for instance, by Peter Markie (1994), at least in relation to some of the notions of substance he distinguishes). Edward Slowik (200I) and Marleen Rozemond (20 I I) also defend pluralist views, but it is not clear to me to which of these varieties their views belong.

\section{The textual evidence}

We have just presented three different views concerning how many corporeal substances there are for Descartes. Now, what reasons can be given for adopting one of these views rather than the others? And, in particular, what evidence can we find in the Cartesian corpus as regards these issues? As one would probably expect, given how I have described the situation, the available evidence is far from clear, as there are different texts and considerations that

${ }^{2}$ This is, for instance, how Cottingham discusses Descartes's notion of extended substance: 'There is a clear contrast here with the traditional Aristotelian conception of the world as composed of a large number of individuals, each of which is regarded as a particular substance (for Aristotle, an individual horse or tree or chair qualifies as a substance). Instead Descartes offers a radically monistic view of corporeal substance. The physical universe is a single indefinitely extended thing: 'The world, that is, the whole universe of created substance, has no limits to its extension'; 'the matter whose nature consists simply in its being an extended substance occupies all imaginable space' (Principles II, 21 and 22; AT VIII-A, 52)' (I986, 84-5). It is interesting to note here that the passages that Cottingham quotes to substantiate his claim are relevant to the issue of the world's being indefinitely extended, but not to its being the only one substance, for which claim he does not offer any textual evidence. Consider also how Williams puts forward a basically similar view: 'Plurality genuinely occurs on the mental side at level I [of substances]; while on the material side, for Descartes, everyday references to a plurality of material substances really unmarket to level III [of modes], and are a way of speaking of what, more basically regarded, are modes of what, at level I, is just one extended substance, the whole physical universe (I978, 128)'. Cf. also Gueroult (I953, vol. 1, 103-18). 
speak in favour of each of these views. Any interpretation of Descartes' views on extended substances, then, faces the challenge of giving a coherent reading of an heterogeneous series of texts, which, given the purpose of this paper, it will be convenient to divide into two different groups, according to whether they give prima facie evidence for, or against, the thesis that (some kinds of) individual objects are substances.

\subsection{Texts favouring Pluralism}

Let us consider first a series of texts that seem to favour the view according to which some individual objects are substances:

[1] Strictly speaking, a real distinction exists only between two or more substances; and we can perceive that two substances are really distinct simply from the fact that we can clearly and distinctly understand one apart from the other... [...] For example, even though we may not yet know for certain that any extended or corporeal substance exists in reality, the mere fact that we have an idea of such a substance enables us to be certain that it is capable of existing. And we can also be certain that, if it exists, each and every part of it, as delimited by us in our thought, is really distinct from the other parts of the same substance (Principles I 60, AT VIII-A, 28)

[2] With regard to the clear and distinct elements in my ideas of corporeal things, it appears that I could have borrowed some of these from my idea of myself, namely, substance, duration, number and anything else of this kind. For example, I think that a stone is a substance, or is a thing capable of existing independently, and I also think that I am a substance (Third Meditation, AT VII, 44)

[3] [...] perhaps some accidents, considered in themselves, may be substances, as clothing is an accident with respect to a human being (to Regius, AT III, 460)

[4] As for the difficulty you mention, concerning the Blessed Sacrament, I have no reply except that if God puts one purely corporeal substance in place of another, like a piece of gold in place of a piece of bread, or one piece of bread in place of another, he changes only the numerical unity of their matter by bringing it about that numerically the same matter, which was gold, takes on the accidents of the bread [...] (to Clerselier, AT IV, 372)

${ }^{3}$ Throughout the paper I follow the translations by Cottingham, Stoothoff, Murdoch and Kenny in CSMK. 
[5] I am aware that certain substances are commonly called 'incomplete'. But if the reason for calling them incomplete is that they are unable to exist on their own, then I confess I find it self-contradictory that they should be substances, that is, things which subsist on their own, and at the same time incomplete, that is, not possessing the power to subsist on their own. It is also possible to call a substance incomplete in the sense that, although it has nothing incomplete about it qua substance, it is incomplete in so far as it is referred to some other substance in conjunction with which it forms something which is a unity in its own right.

Thus a hand is an incomplete substance when it is referred to the whole body of which it is a part; but it is a complete substance when it is considered on its own. And in just the same way the mind and the body are incomplete substances when they are referred to a human being which together they make up. But if they are considered on their own, they are complete (Fourth Replies, AT VII, 222)

As we remarked above, these are just a few among many texts that seem to testify to Descartes' belief in the substantiality of various particular individual bodies and, specifically, of some ordinary objects. Indeed, many recent authors (for instance, Slowik (200I) and Rozemond (20 I I)) have precisely drawn attention to how many times Descartes talks of particular bodies as substances, and have expressed surprise on that account that the Monist interpretation had come to establish itself as the textbook view on the matter. We'll consider later some other reasons for this interpretation below. ${ }^{4}$ But, in any case, there's one important thing that should already be noted in relation to these texts, namely that, striking though that might be, all of the interpretations listed above, with the exception of one brand of Pluralism ((iii b), which is the view to be defended here), fail to accommodate texts [2] - [5] (and the many other similar ones scattered in the Cartesian corpus). Text [1] is a little bit different from the others, as it does not mention any ordinary object, but just parts of extension "delimited by us in our thought", as individual substances; but, in any case, it

${ }^{4}$ John Heil has suggested to me, in conversation, that at least some of the remarks where Descartes talks of ordinary objects as substances may be just understood as ways of trying to make his meaning of 'substance' clear, by means of traditional examples, but that they should not be taken strictly as expressing his official views on the extension of 'substance' or of 'extended substance'. A similar point has also been made by Stuart (I999, 100), when he says that 'Descartes must therefore be regarded as speaking lightly when he claims that stones, hands, and articles of clothing are substances'. I won't claim that this possibility can be ruled out for all the texts just discussed; but I'd like to notice that this view seems highly implausible at least for some of these texts - for instance, for texts [1] and [5] above, whose contexts are precisely ones in which Descartes is trying to explain his technical notion of real distinction (a point similar to mine here has already been made by Rozemond 201 I, 241). 
is also clear that all Non-Pluralist interpretations (that is, the Monist and the Nihilist views) seem prima facie unable to accommodate this text and, therefore, the whole group of texts we have considered so far.

\subsection{The Synopsis passage}

What can Non-Pluralists offer by way of textual support for their view? It seems that the clearest textual evidence for such views, and perhaps the whole of such evidence, consists in one single text, text [6] below, taken from the Synopsis to the Meditations:

[6] First, we need to know that absolutely all substances, or things which must be created by God in order to exist, are by their nature incorruptible and cannot ever cease to exist unless they are reduced to nothingness by God's denying his concurrence to them. Secondly, we need to recognize that body, taken in the general sense, is a substance, so that it too never perishes. But the human body, in so far as it differs from other bodies, is simply made up of a certain configuration of limbs and other accidents of this sort; whereas the human mind is not made up of any accidents in this way, but is a pure substance. (...) And it follows from this that, while the body can very easily perish, the mind is immortal by its very nature (AT VII, 14, my emphasis).

Even though this text might prima facie give some support to the Monist and Nihilist readings of Descartes on material substance, the text is not as clear as one could hope, and some work must be done if it is to count in favour of any view - in particular, as we will see below, some work must be done to clarify the meaning of the phrases we have italicised in our quotation. But, in any case, the text certainly seems to lend some support to the denial of the status of substance to ordinary objects, suggesting, as it does, that human bodies are not substances. Nevertheless, it should also be borne in mind that in some other texts, such as [5] above, Descartes also explicitly affirms that human bodies are substances. So that, again, the evidence seems at best far from conclusive, and a careful study of their contexts and significance is called for.

Be that as it may, and even before going on to discuss some of them in some more detail, one striking fact regarding these texts should be noted, namely, that at least from a merely quantitative point of view, the textual evidence seems to be overwhelmingly in favour of a Pluralist reading - and, in particular, in favour of one that counts ordinary objects as substances. But, before reaching any conclusive position on the issue, the weight and meaning of the Synopsis passage must be ascertained. 


\section{How to interpret the Synopsis Passage}

In any case, the Synopsis passage (text [6] above) has been something like a battlefield for the different positions concerning how many corporeal substances there are for Descartes, as it is supposed to be the main textual support for many of them. Of course, this is in part possible because the meaning of the text is not as clear as one might wish, which also accounts for the fact that people has to connect it to other Cartesian texts and/or well established theses when trying to figure out its meaning.

In connection with the issue we are discussing here, the diverse interpretations of [6] mainly depend on different ways of understanding the clause italicised in our quote, namely, the phrase "... that body, taken in the general sense, is a substance" (corpus quidem in genere sumptum esse substantiam). In particular, there are two main points to be settled:

(a) How one should understand 'body, taken in the general sense' and

(b) How one should understand 'a substance' (or, better, the Latin term substantiam).

(a) What's the meaning in this context of 'body, taken in the general sense'? Let us notice first that, contrary to what will happen in relation to 'substance', it doesn't really matter very much whether 'body' is taken here as a mass term or as a count noun; the Nihilist could take any stance here, for he can say that the 'is' in 'is (a) substance' is an 'is' of predication, not one of identity, so that, even if 'substance' is a mass term, 'body' could just as well be a mass term or a count noun (given that one could also characterize by means of a mass term something referred to using a count noun, as in 'That patch of liquid over there is water'). For simplicity's sake, though, let us just assume that it is always a count noun. But now, what does it mean to take body 'in the general sense'? Pluralists and Monists take two clear, contrasting sides on the issue: for the Pluralists, it seems, to take body in the general sense just consists in taking it as something that satisfies a general notion of body, one that may be used to characterize any (or, at least, many) different sections of extension: 'body' is here taken as a general term, that may be applied to a plurality of things in virtue of their having a bodily nature. For the Monists, on the other hand, Descartes adds to 'body' the phrase 'taken in general' to make it clear that it refers in that context to the sum of all sections of body, that is, they think that 'body, taken in general' designates in that context the whole extended world. ${ }^{5}$

${ }^{5}$ This reading of 'body, taken in general' is explicitly adopted by Secada in the context of his endorsement of a Monistic view on corporeal substance. In effect, after stating that 'there 
(b) There are also some decisions that have to be made in relation to 'substance', $\mathrm{o}$ 'a substance'. The fact that in Latin there is no (definite or indefinite) article makes the meaning of substantiam here somewhat indeterminate. In particular, we find that, while the Nihilists understand 'substance' (at least when applied to corporeal substances), as already noted, as a mass term, on the model of 'water', Monists and Pluralists alike understand it as a count noun, meaning, in that context, one substance. But there are really two different issues behind this disagreement, clumsily expressed in these terms. On the one hand, the issue is presented as a grammatical point, as an issue of what kind of term 'corporeal substance' is; but there should really be no dispute at this level, given that both 'substance' and the composite phrase 'corporeal substance' are clearly used by Descartes as count nouns: not only is this reading assumed in the French translation of the Principles, which was revised by Descartes, where substantiam is in this passage translated as une substance (AT IX-B, 10); such phrases are also clearly used in that way in many other contexts, such as in the mention of 'two or more substances', even for the case of corporeal substances, in the definition of real distinction in Principles I 60 (text [1] above). But there is a further, deeper issue, which concerns not so much the logical or grammatical behaviour of 'corporeal substance', but the connection of the notion of (corporeal) substance with the notion of individuation. And, at this level, what has been presented as a disagreement between a "count term" or a "mass term" interpretation eventually reduces to the question of whether the conditions that something has to fulfil for it to count as a substance also involve criteria on how to individuate it, that is, on how the boundaries between different substances are to be drawn. So, for instance, if the notion of a substance is related to, say, a notion of form, or of functional unity among its parts, then if one describes something as a substance, one is committed to its being determined whether some particular section of extension is included in it or not, namely, either because it is connected or not functionally to it, or because it is informed or not by the same form. If one believes, then, that the notion of substance is related in this way to that of individuation, one has then a "count term" view on 'substance'. On the contrary, if one does not think that there is such a connection, one would have a "mass term" view. As we already said, though, that would be a misnomer, given that mass terms (or "mass notions") are not the

is strictly only one body which is "this world or the whole of corporeal substance" (AT VIII-A, $52)$ ', and after quoting Descartes acknowledging that 'this word 'body' is extremely equivocal (AT IV, 166)', he says that, in that context, "'body" is "taken generally", that is, to mean all the parts of the single corporeal substance' (2006, 83). Chappell (20 I0, 258-9) also thinks this phrase has to be read so as to favour Monism. See also Rozemond (201 I, 248-9) for discussion of this interpretation and a clear statement of the pluralist alternative reading sketched above. 
only terms that do not imply by themselves criteria of individuation: so called 'dummy sortals', for instance, or adjectival notions, also fail to be so connected with criteria of individuation. The interesting issue, then, to which the discussion concerning whether 'corporeal substance' is a mass term ultimately points, and which is highly relevant for our purposes here, is whether the notion of substance is rich enough so as to include criteria of individuation. In order to answer this question, we must turn now to an examination of the Cartesian notion of substance.

\section{Substance}

\subsection{Two notions of substance}

It is usual, in the secondary literature on Descartes, to begin the discussion of his views on substance by noticing that he gives two apparently different definitions of the notion, namely, on the one hand, (i) a definition of substance as an independent entity and, on the other hand, (ii) a definition of substance as an ultimate subject of attributes. ${ }^{6}$ Indeed, Descartes seems just to express here two strands of traditional thought about substance, which can be arguably traced back at least to Aristotle, namely, substance's alleged capacity to exist apart, and substance's being something that neither exists in, nor is said of, other things. ${ }^{7}$ Several Cartesian texts testify to the presence of these two strands in his thinking about substance. The conception of substance as an independent entity is present, for instance, in the following text, which constitutes the official definition of substance in the Principles:

[7] By substance we can understand nothing other than a thing which exists in such a way as to depend on no other thing for its existence (Principles I, 51; AT VIII-A, 24) ${ }^{8}$

${ }^{6}$ See, for instance, Kemp Smith (1953, 313-4) and Woolhouse (1993, 15). Other authors find in Descartes' work, besides these, some further notions of substance. So, for instance, Markie $(1994,63)$ finds also a third, more restrictive notion of substance, that of pure substance, while Chappell (2010) distinguishes three different definitions (one in the Third Meditation and the Second Replies, a second one in the Fourth Replies and a still further one in the Principles) which, nonetheless, can be combined, in his view, to provide a unified account.

${ }^{7}$ On the former character, cf., for instance, Aristotle, Metaphysics XII, Chapter 5, 1070b1071a; on the latter, Categories, Chapter 5, 2a $11 \mathrm{ff}$.

${ }^{8}$ It has been noted that if 'thing' means (as sometimes with Descartes) the same as 'substance', the definition would be circular (and indeed, such a formulation, substituting 'substance' for 'thing', is used by Descartes in the Fourth Replies, AT VII, 226). I take it that, in that 
But in many other texts we find another characterization of substance, according to which it is described as a subject of, or as what supports, properties; as, for instance, in the following one, taken from the geometrically ordered Appendix to the Second Replies:

[8] Substance. This term applies to every thing in which whatever we perceive immediately resides, as in a subject, or to every thing by means of which whatever we perceive exists. By 'whatever we perceive' is meant any property, quality or attribute of which we have a real idea" (Second Set of Replies, AT VII, 161)

Before discussing any further these texts, and other relevant ones in the Cartesian corpus, let me pause briefly to say a few words regarding two possible strategies to explain away this apparent divergence: on the one hand, it would be implausible to explain the divergence as following from a development in Descartes' thought, given that the two characterizations coexist in some of his works, even in the very same page: for instance, a description of substance as subject of properties appears in a discussion of our knowledge of substances in $\$ 52$ of Principles $\mathrm{I}$, that is, in the paragraph immediately following the paragraph where text [7] appears. On the other hand, one could suggest that, while one of these notions may provide for Descartes a genuine definition of substance, the other would offer no more than an informal characterization of the things so defined; but it should be noticed, against this, that texts [7] and [8] are both offered (in their respective contexts) as definitions of substance. ${ }^{9}$

This situation requires us to try to figure out how these two notions of substance relate to one another. In the rest of this section, I elaborate first these two different characterizations of substance, and then proceed to the task of trying to assess what kind of relationship there is between them.

context, 'thing' must be understood as 'entity' (cf. Rosenkrantz and Hoffman i99i, 837; MARKIE I994, 66).

${ }^{9}$ Of course, one could still come up with rather more subtle narratives concerning the evolution of Descartes' thought to defend the idea that both characterizations are not on a par; for instance, one could suggest that, while he defines substance as a subject in 1641, he changes his mind, rejects that definition, and defines it as an independent entity in 1644, retaining the former definition now as a non-defining characterization. This would be a very subtle change, but in any case one that does not affect the main point that Descartes believed for some time that substances satisfied both characterizations, no matter how he conceived the question of priority, so that we still face the problem of understanding how the two notions relate to one another. 


\subsection{Substance as an independent entity}

Text [7], then, is the standard formulation of the concept of substance as an independent entity. But it remains to be clarified, in particular, what kinds of independence (and, correspondingly, of dependence) are at stake in this formulation. The kinds of dependence usually discussed in connection to Descartes' notion of substance as an independent entity are mainly those of causal and inherential dependence; but mereological dependence (the dependence of something on its proper parts) and essential dependence (that is, the dependence of a substance on its attributes, or on its essential properties in general) are also sometimes mentioned in this connection. Let us consider the evidence for supposing that any of these notions is present in Descartes discussions of independence.

It seems plausible, in the first place, to suppose that the dependence at stake in the definition of substance is at least to some extent of a causal kind. In effect, after introducing the notion of substance in [7], Descartes goes on to say the following:

[9] And there is only one substance which can be understood to depend on no other thing whatsoever, namely God. In the case of all other substances, we perceive that they can exist only with the help of God's concurrence (Principles I, 51; AT VIII-A, 24)

Since all other things except God are said to fail the stated definition because they are not completely independent in the relevant sense, and since this failure is brought about by those other things being causally dependent on God (God's concurrence being plausibly understood as a kind of causal relation), then it seems plausible to suppose that the relevant sense of independence must be, at least to some extent, causal independence. But this admission, even if it is correct, does not settle conclusively the issue: on the one hand, it might be the case that the relevant notion of dependence is a broader one, including, but not being exhausted by, causal dependence. ${ }^{10}$ Indeed, as will become clear later, I think this is actually the case. On the other hand, not every kind of causal relation may be intended by Descartes to be relevant in this connection; in particular, there is a distinction among two different kinds of effects that seems significant here, namely, one that Descartes makes in the Fitfth Replies

${ }^{10}$ This point has been very well argued for by Rodriguez-Pereyra $(2008,84-5)$ against Stuart ( $1999,88 \mathrm{ff}$.), who had defended the idea that the notion of dependence involved in the definition of substance as an independent entity is (mainly) a causal one. 
between something's being a cause of the coming into being of something else, on the one hand, and something's being a cause of the being of something else (or of its remaining in existence), on the other.

[10] When you deny that in order to be kept in existence we need the continual action of the original cause, you are disputing something which all metaphysicians affirm as a manifest truth - although the uneducated often fail to think of it because they pay attention only to the causes of coming into being and not the causes of being itself. Thus an architect is the cause of a house and a father of his child only in the sense of being the causes of their coming into being; and hence, once the work is completed it can remain in existence quite apart from the 'cause' in this sense. But the sun is the cause of the light which it emits, and God is the cause of created things, not just in the sense that they are causes of the coming into being of these things, but also in the sense that they are causes of their being; and hence they must always continue to act on the effect in the same way in order to keep it in existence (Fifth Set of Replies; AT VII, 369) ${ }^{11}$

Taking into account the examples discussed, it seems that it is only the causal dependence on God of something's being that is clearly involved in the definition of substance in the $\$ 51$ of Principles (text [7] above). Besides, it should also be noticed that, as the examples in text [10] suggest, if the relevant notion of dependence included also the causal dependence connecting a cause with something's coming into being, then one should conclude that most ordinary objects would not count as substances. The fact that there are plenty of texts in which Descartes describes such objects as substances would count against taking this kind of causal relation as included in the relevant notion of dependence (unless there are stronger reasons to the contrary). The relevant notion of dependence seems to be, then, the one that takes place between something and what sustains it in existence.

What about inherential dependence? Taking into account different remarks on the notion of substance by Descartes, some of which we have already quoted, it does seem to be an important part of what it means to be a substance that, in contrast to some created entities (namely, modes) that do depend for their existence on inhering in some other things (namely, substances), substances do not depend on other things in just this way. This is most clearly expressed in an addition to the French version of Principles I, 51:

${ }^{11}$ A similar contrast between the relation of a builder to the house he builds, on the one hand, and of God to myself as his creature, on the other, is discussed again in the Conversation with Burman (AT V, 156). 
[11] In the case of created things, some are of such a nature that they cannot exist without other things, while some need only the ordinary concurrence of God in order to exist. We make this distinction by calling the latter 'substances' and the former 'qualities' or 'attributes' of those substances (AT IX-B, 47)

It is clear that the relation implicit here is that of inherence, which is certainly a relation different from that of concurrence also mentioned in this context (which, as we saw, is a kind of causal dependence). But what I would like to stress now is rather that, notwithstanding the many differences that one could certainly find between these two relations, they also seem to have much in common when one takes them as kinds of dependence: in particular, it seems that we have in both cases a relation in which something supports, or sustains, something else in existence. This becomes also apparent in Descartes' description, in text [8] above, of the kind of dependence properties have on substances: remember that he says there, not only that a substance is that in which whatever we perceive immediately resides, as in a subject', which would refer to a "pure" notion of inherence, so to speak, but also that a substance is that 'by means of which whatever we perceive exists' (my emphasis). This phrase suggests, in my view, that a sort of active, causal-like relation of sustaining or of maintaining in existence is integral to Descartes' view of inherence, so that the notions of concurrence and inherence are not really so far away from one another as they are usually taken to be. Of course, I do not intend to deny the important differences there are between causal and inherential sorts of dependence, to which we will turn our attention presently. But it might still be the case, and I'd like to suggest it is actually the case, that there is a common core to both relations, and that this core is precisely the sort of dependence relation that is relevant to the definition of substance - and, indeed, that this relation is the one that articulates all of Descartes' ontological categories.

Let us pause now to consider the differences between the two kinds of dependence we have focused on so far. Consider the example of the sun and the light in text [10]. I take it that the main difference between the relation between the sun and the light, on the one hand, and the relation between, say, the sun and its shape, on the other, is that whereas the shape is a necessary constituent of the sun, in the sense that it depends at least generically on its having one shape or another, the case is different concerning the light, whose production does not seem to be required for something to count as the sun. ${ }^{12}$

${ }^{12}$ Of course, I am commiting myself to the validity of this point only as regards an usual, intuitive appraisal of the sun's relation to its shape, on the one hand, and the light it emits, on the other. Whether this appraisal is actually correct is controversial, and depends, among other things, on how one understands the relation between properties and causal powers or laws of 
But, even if these are important differences, there are good grounds for supposing that, quite apart from that, what is at stake in both cases is a relation of sustaining, or of being a support, or a ground, for something's existence, that seems to me to be the notion of dependence behind the definition of substance as an independent entity. There are two main grounds to accept, it seems to me, besides the textual support already offered, such a view. On the one hand, it helps understand Descartes' attitude to his different definitions of substance: he never seems to have thought that those different definitions, as represented by the apparently dissimilar ones presented in texts [7] and [8], are in conflict with one another; but, in that case, he must think that the notions of dependence and inherence that appear in them are not as radically diverse as has sometimes been thought (I'll return to this below). On the other hand, it may explain his complete neglect, in the context of the characterization of substances, of other dependence relations that have been sometimes mentioned in the literature, and that have been the focus of recent work on grounding and dependence - mainly, the dependence of a substance on its proper parts, and on its essence. The discussion of these two further kinds of dependence will complete our discussion of substance as an independent entity.

Let us begin by considering the relation between a substance and its essence or, in Cartesian terms, its principal attribute. It is sometimes assumed that this relation is problematic in the context of a definition of substance as an independent entity because, when discussing the distinction of reason (Principles I, $\$ 62$ ), Descartes affirms that it is impossible for a substance to exist (and to be conceived of) without its attributes, and that it is impossible for its attributes to exist (and to be conceived of) without the substance; and this is supposed to imply that there is some kind of mutual dependence between substances and their (principal) attributes. Now, if were is true that substances depend on their attributes, that would conflict with Descartes' clearly stated view that created substances depend only on God for their existence. Some authors have tried to solve this conflict by arguing that, for Descartes, substances and their (principal) attributes are indeed identical (Rodriguez-Pereyra, 2008). This seems to me an unsatisfactory solution, for reasons I cannot discuss fully here - it implies, for instance, that all attributes are identical to one another. ${ }^{13}$ But the discussion on dependence above seems to provide a much more promising solution of this puzzle: if we suppose that the notion of dependence

nature, on the one hand, and also the relation between the conceivable and the possible, on the other. Given that the example is only taken an illustration, I think I can avoid entering into these topics here.

${ }^{13}$ I discuss this more comprehensively in "Descartes on Attributes" (unpublished). 
relevant to the definition of substance is the richer, more specific, and asymmetrical one of sustaining something in existence, then we could say that the dependence allegedly involved in the distinction of reason does not affect the fact that a substance depends only on God, because there are two different notions of dependence involved in the (apparent) conflict: on the one hand, the stronger one of sustaining in existence, which is the only one relevant for the characterization of substances and regarding which it is true to say that substances depend only on God; on the other hand, a purely modal notion of dependence understood in terms of necessary coexistence which, even though in fact relates substances and attributes, is irrelevant for the characterization of something as a substance.

The relation between a substance and its parts is somewhat different. Note in the first place that it does not seem to have a single modal profile in the different cases, so that the relation could not be captured in simple modal terms: while Descartes thinks that in some cases, that of the so called "bodies in general", particular sections of matter do have their parts essentially, in some other cases, for instance, that of human bodies, this is not so (see text [15] below). In any case, if our hypothesis is correct that the only notion of dependence that is relevant for the definition of substance is that of sustaining something in existence, then that would explain Descartes' clear neglect of the relation between a substance and its parts in this context. Certainly, it seems implausible to suppose that the parts support or sustain in existence the substances they conform in a sense remotely akin to that in which that substance is sustained in existence by God. Indeed, Descartes clearly implies that wholes and parts are on a par from an ontological point of view: whole human bodies and human hands are both characterized by him as substances (see text [5] above).

\subsection{Substance as subject of properties}

In other texts, such as [7] above, we find a rather different notion of substance: that of substance as a subject of properties, that is, as one thing in which whatever we perceive immediately resides'. In a sense, as Markie had remarked, this notion of substance is 'almost the flip-side of the concept of substance [as an independent entity]', focusing, as it does, not on the independence of substances as regards other entities - and, in particular, in this case, as regards modes - but, on the contrary, on the dependence other things have on substances. As Markie says: 'Being a substance [in the sense of a subject] consists, not in being independent of other things, but in being something of which other things are not independent, something on which they depend as a subject for their existence' (1994, 75). Given that the relation focused on in 
this characterization of substance is just the counterpart of the independence of substances as regards modes (and, indeed, as regards properties in general), and that the asymmetric relation made up from these two aspects exhausts the connection between substances and modes, it is not surprising that the notion of substance as subject has been found to be coextensive with the notion of substance as an independent entity when restricted to created substances that is, to things that depend only on God for their existence (MARKIE I994, 78). Nonetheless, even if this is so it is important to notice that it is not prima facie obvious that whatever falls within one of these concepts also falls within the other: that is, it is not implied by the idea that something is independent of some things that there are some further things which depend on it: it just turns out, in the ontological scheme recognized by Descartes, that what is only dependent on God is such that all the other things there are (that is, properties in general, which are identified directly on the basis of our experience) depend on them. And this dependence, as we suggested above, is plausibly understood as a particular variety of the relation of being sustained in existence. On the other hand, finally, further details which would have to be settled if we are to have a definite image of substances so characterized, such as whether we should understand the subject of properties as a substratum, or as the whole concrete particular (a kind of ambiguity that besets subject theories of substance since Aristotle), may be safely left aside here: the different answers to such questions are orthogonal to the problem we are dealing with in the present paper, so that a discussion of them would be beside the point here.

\subsection{A unified notion of substance?}

What we have said so far concerning these two characterizations of substance suggests, in my view, that they are arguably much more closely connected than has been usually assumed. I have suggested, indeed, on the one hand, that the notion of dependence focused on in the characterization of substance as an independent entity is the rather specific one of supporting or sustaining something else's existence; and, on the other hand, I have also suggested that the relation of inherence relating modes and substances is nothing more than one specific form that this relation of dependence may take. Now, if this suggestion is right, then this notion of sustaining in existence is the one central notion behind the different characterizations of substance in the Cartesian texts: and it is also arguably the notion that articulates the different ontological categories, by locating created substances in the middle position in the ontological hierarchy, below God, on the one hand, because they are always being sustained by Him in existence, and above modes (and properties in general), 
on the other hand, because substances are required to sustain modes in existence (and, on the other hand, they are not sustained by modes). ${ }^{14}$ These last two aspects of the asymmetrical relation of inherence, then, are (part of) what gets described in the two different characterizations of substance: the independence of substances from modes in the independence conception, and the corresponding dependence of modes on substances in the subject conception. This leaves us with a fairly unified notion of substance, articulated in terms of relations of dependence: a substance is something sustained in its existence only by God (and, therefore, not sustained in existence by any other created thing); and, besides, a substance is something which sustains the properties we perceive. Having clarified in this way the Cartesian notion of substance, we must examine next its connection to the problems about material substances we were considering.

\section{Corporeal substances}

What consequences can be drawn from our discussion of substance for the issues regarding corporeal substances we were discussing? In my view, the main point to take into account is that the notion of substance is a rather thin one, one that imposes very few constraints on whatever is to be characterized as such: it just allows us to admit as a substance any entity playing a certain functional role but, beyond the requirement of fulfilling that role, it doesn't characterize such entities any further. As Markie had remarked, in relation both to the notion of substance as an independent entity, and as a subject of properties, the notion of substance does not really have much metaphysical content. This is what he has to say in connection with Descartes' contention that he is a substance:

[12] His claim to be such a substance is consistent with his being material and with his being immaterial. It is consistent with his being a bare substratumqualities combination, with his being a bundle of qualities, and with his being neither. It is consistent with his being divisible into other substances [here, as independent entities] and with his not being so divisible... (1994, 73)

${ }^{14}$ We may note, in passing, that the fact that Descartes seems to presuppose in his Third Meditation proofs of the existence of God (AT VII, 40) a single ontological hierarchy articulated by some notion of dependence seems to favour the view that there must be a central core behind the different notions of dependence involved (otherwise, what we get as a result would not be a single, unified, hierarchy). 
So, no matter how an entity might be further characterized, it is enough for it to count as a substance that it occupies the role of what sustains, or is the ground of, the properties it has, and that it is something not grounded on, that is, independent of, anything but God. But then, if this is right, it seems to corroborate what the many Cartesian texts quoted above already strongly suggested, namely, that there is no reason to deny substance status to individual bodies - and, in particular, to deny such status to ordinary objects. Indeed, it seems reasonable to suppose that such bodies are for Descartes things that are sustained in existence only by God, and are also things that sustain, although are not sustained by, their properties. Indeed, what is important to notice in this context is that it doesn't seem possible to extract, from the requirements for being a substance, any criterion for drawing boundaries between substances; that is, no specific principle of individuation follows from them.

Moreover, our discussion of substance provides us with a powerful tool to reject the two main arguments for denying substance status to ordinary objects that one can find in the literature. The first of these, sometimes called "The Spinozistic Argument" (Rozemond 20 I I), and which is one of the main arguments that have been adduced in favour of a Monistic reading of Descartes, may be found in the following passage by Spinoza:

[13] For if corporeal substance could be so divided that its parts were really distinct, why, then, could one part not be annihilated, the rest remaining connected with one another as before? And why must they all be so fitted together that there is no vacuum? Truly, of things which are really distinct from one another, one can be, and remain in its condition, without the other. Since, therefore, there is no vacuum in Nature (a subject I discuss elsewhere), but all its parts must so concur that there is no vacuum, it follows also that they cannot be really distinguished, i.e., that corporeal substance, insofar as it is substance, cannot be divided (Spinoza, Ethics, Part I, Scholium to Prop. 15; G II, 59)

The argument seems to be as follows:

(1) Substances are things that exist independently of any other thing (unless, in the case of creatures, they depend on God) (Premiss)

(2) A vacuum is impossible (Premiss).

(3) Any finite section of extension cannot exist unless the whole indefinitely extended corporeal world exists (from 2).

(4) Any finite section of extension depends on other corporeal things (from 3, meaning of 'depend').

(5) Any finite section of extension is not a substance (from 1, 4). 
It seems clear enough that Premises (1) and (2) are accepted by Descartes: (1) is what he actually gives as his definition of substance in Principles $\mathrm{I}, \$ 51$ (text [7]), and he endorses (2) in Principles II, $\mathbb{\$} 16$. So, could one resist this argument? And how?

The obvious candidates for rejection are the transition from (2) to (3) ('(2) to (3)' in what follows), and the transition from (3) to (4) ('(3) to (4)'). (2) to (3) might perhaps be resisted, but its rejection would involve us in controversial and difficult issues, such as that of the modal status of some theses in Descartes' physics. Taking into account our previous discussion of the notion of substance, I propose to concentrate efforts on (3) to (4) instead. I think that one could appeal to some features of the notion of dependence relevant for Descartes' definition of substance to invalidate this transition.

First of all, we should notice that Descartes uses in his characterization of the ontological categories relations of dependence that only relate individuals (even when the notion of dependence is understood in purely modal terms). This is clear in the case of substances and modes: when it is said that a substance is independent of a mode that inheres in it, what is meant is just that that particular substance is independent of that particular mode (and, on the other hand, when it is said that the mode depends on the substance, what is meant is that that particular mode depends on that particular substance). This is connected to the fact that a substance is not generically independent from modes, because substances depend for their existence, in this modal sense, on their having some modes or others (for instance, a body requires for its existence some shape or other); so that, when it is said that substances are independent of modes, the only thing that can be meant is that they are independent of individual modes. Similarly, in the vacuum case, one could say that a certain particular body requires some body or other to fill the unlimited extension around it, but this does not mean that it requires that a certain particular body, that actually happens to fill it, does so. The requirement, or the dependence here, is only generic: a body requires for its existence that some body or other fills the indefinitely extended space around it, but its existence does not require the presence of any particular body. If this is correct, then (4), at least in the sense in which it must be understood in order to be able to justify in its turn (5), does not follow from (3), because, while (3) states a purely generic requirement for the existence of a section of body, (4) expresses a stronger requirement, that of the existence of particular individuals. ${ }^{15}$

${ }^{15}$ A similar strategy, inspired in comments by Leibniz intended for de Volder (in a draft of June 23, I699) is defended (slightly differently) by Rozemond (201 I, 255). 
This line of defence against the Spinozistic Argument is available even for someone who takes the relevant notion of dependence in simple modalcum-existential terms, as necessary coexistence. But, as we saw, the notion of dependence involved in the characterization of substance seems to be a richer one, the notion of being sustained in existence. A particular body, then, if one takes this richer notion, would fail to count as a substance only if it depends in this way on something other than God. But do Spinoza's considerations imply that bodies depend on some other bodies in this way? It seems clear to me that bodies do not stand to other bodies in this kind of dependence, that is, that a body is not sustained, or kept in existence, by other bodies, even if it is correct to suppose that it cannot possibly exist without those other bodies (or, generically, some bodies or other). The picture that emerges from these considerations is then one in which each individual body depends in a particularized way, so to speak, on God, and on God alone, in the sense that each body is sustained in existence by a specific act of God. This particularized character of the dependence, on the other hand, seems to be what is at stake in Descartes' countenancing the possibility of God's annihilating one piece of matter (through denying his concurrence) while preserving another (cf. Principles II, $\$ 18$, AT VIII-A, 50). ${ }^{16}$

Recent work by Marleen Rozemond (20II) on the notion of real distinction is in agreement with this hypothesis, so that her independent results help to establish its plausibility. Although she focuses more on the notion of real distinction, and not so much on that of substance, the connection between the two notions is tight enough for theses on one of them to be relevant for the other. What Rozemond defends in that paper, drawing from a discussion of the notions of distinction and separability in Suárez, is that the separability required for two items to be really distinct of one another may be weaker than separability in the sense of one thing being able to exist without the other thing existing, so that two things may still be really distinct through not depending on one another in some suitable, stronger sense, even though it is impossible for one thing to exist without the other existing (as in the case of (substantial) creatures and God: they are really distinct, even though a creature cannot exist without God existing). I take it that Rozemond's results, based

${ }^{16}$ Of course, given God's simplicity, it would be strictly wrong to speak of "specific acts" of God, if this is taken to imply that they are different acts, just as it would be strictly wrong to talk about his different attributes (cf. Principles I, $\$ 23$, AT VIII-A, 14: 'And even his understanding and willing does not happen, as in our case, by means of operations that are in a certain sense distinct from one another; we must rather suppose that there is always a single identical and perfectly simple act by means of which he simultaneously understands, wills and accomplishes everything'). All differences in God are thus ascribed to him as a result of our considering his effects from our perspective. 
mainly on contextual evidence about a distinct but related notion, lends more plausibility to our own account.

The Spinozistic Argument alludes to a certain (alleged) structural dependence between particular pieces of body and all other pieces of body. A further argument sometimes used against Pluralism, and in particular against the thesis that ordinary objects count as substances for Descartes, arises from taking into account, as relevant for the definition of substance, the causal dependence between the existence of some such objects and some other bodies. Matthew Stuart thinks this favours his own pluralist take on corporeal substances, according to which quantities of matter, but not ordinary objects, are substances. This is why, according to him, ordinary objects should not be seen as substances:

[14] Do human bodies, tables, and planets count as secondary substances on the causal reading of the independence criterion? It would seem that they do not. For even if each of them is causally dependent on God for its preservation, none is causally dependent on God alone at every moment of its existence. Human bodies are brought into existence by the sexual activities of human beings; tables are brought into existence by the labor of woodworkers; and, according to Cartesian physics, planets are brought into existence by huge, spinning vortices of celestial matter. Furthermore, there are occasions on which not only the creation but also the continued existence of a physical object depends on the activity of a created thing. For example, the continued existence of a fragile glass vase might depend on the exertions of a person who keeps a weight from crushing it. This result accords with Descartes's denial, in the Synopsis passage, that the human body is a substance (I999, 90)

One main problem with this view lies in its causal reading of dependence: even though there is, as we have seen, a causal strand to the notion of dependence relevant for a characterization of substance, it is of a quite specific nature, and one that also overlaps to a certain extent with the converse of inherence, namely, the relation of sustaining something in existence. But, as we saw in connection with text [10] and its distinction between the cause of the coming into being of something and the cause of its mere being, only the latter is relevant in this context; and, on the other hand, it is clear that the examples of causal dependence discussed in text [14] are cases of causes of the coming into being of ordinary objects (or the correlative relation of ceasing to be; the efforts to guarantee the continued existence of the vase are nothing more than intermittent attempts at preventing its destruction). But, if this is correct, it is clear that this specific causal dependence does not prevent ordinary finite objects from 
being substances, given that they are things that are still sustained in existence only by God, and depend in that specific way on no other thing - whereas some properties do depend on (each of) them.

Our proposal concerning corporeal substances could then be summarized as follows: any piece of matter (or extension) is at every moment of its existence a substance because, at every moment of its existence, it is (or it is constituted by) something, namely, a fragment of extension, that depends on God's concurrence, and on God's concurrence alone, to remain in existence, while it also sustains in existence, in the appropriate sense, some other, more dependent beings, such as modes and attributes. ${ }^{17}$ In particular, every ordinary corporeal object (such as a chair or a human hand) would count as a substance, because at every moment it coincides with such a piece of matter or extension. It is important to notice, in this regard, that no more specific condition of individuation or persistence is involved in the notion of a substance as we have construed it, besides the already noticed fact that a substance would cease to exist if God stopped sustaining it through his concurrence. This means that the requirements for being a substance are not strict enough so as to imply that only some particular kinds of material objects may count as substances, while others may not.

The conception sketched above sounds very much like Stuart's own view that only pieces of matter, in Helen Cartwright's sense, are substances (cf. CARTWRight I970). It would seem then worthwhile to try to state more precisely the difference between his view and the one defended here. He bases his view mainly on the Synopsis passage (text [6] above), and an identification of 'body, taken in the general sense' with quantities of matter, on the basis of the following remarks by Descartes, in the context of a discussion of transubstantiation:

[15] First of all, I consider what exactly is the body of a man, and I find that this word 'body' is very ambiguous. When we speak of a body in general, we mean

${ }^{17}$ The form 'it is (or it is constituted by)' in the main text above is a deliberate hedge, by which I imply that I need not take a stand on whether for Descartes constitution is or is not the same as identity - the view defended here is compatible with any of the alternatives, and requires only a change in formulation from one version to the other. On the other hand, I assume that attributes are not identical to the substances of which they are attributes, as many recent commentators have supposed, but that they conform, together with modes, a wider class of properties (a class Descartes never mentions as such, although he sometimes refers to it as the class of 'modes or attributes'). I cannot try to substantiate this view here, although I try to do so elsewhere ("Descartes on Attributes", unpublished). 
a determinate part of matter, a part of the quantity of which the universe is composed. In this sense, if the smallest amount of that quantity were removed, we would judge without more ado that the body was smaller and no longer complete; and if any particle of the matter were changed, we would at once think that the body was no longer quite the same, no longer numerically the same. But when we speak of the body of a man, we do not mean a determinate part of matter, or one that has a determinate size; we mean simply the whole of the matter which is united with the soul of that man. And so, even though that matter changes, and its quantity increases or decreases, we still believe that it is the same body, numerically the same (to Mesland, 9.2.45; AT IV, 166)

I think that this text indeed induces an identification between 'body, taken in general' and 'quantities of matter', if we take this as equivalent to 'pieces of extension'. But, even though Descartes goes on, after introducing this notion, to discuss persistence conditions for quantities of matter, and to contrast these with persistence conditions for ordinary objects, this contrast has no implication as regards the substantial character of ordinary objects, because no specific persistence conditions are relevant for characterizing something as a substance: the text does not imply anything more than that an ordinary object coincides, in each successive stage, with (possibly different) quantities of matter. But the fact that it coincides with a quantity of matter at each stage of its existence is precisely that in virtue of which it is appropriate to say of it, at every stage, that it is a substance: this is unaffected by the fact that, considered as a quantity of matter, it has different persistence conditions than it has when considered, say, as a human body.

\section{Conclusion}

If what I have suggested so far is plausible, the following image of Descartes' view on corporeal substances emerges: any section of matter at any moment counts as a substance, because any section of matter fulfils at that moment the rather slim requirements for being a substance, namely: it is something that sustains its own properties and is itself something only sustained in existence by God. Besides, ordinary objects can also count, according to this view, as substances, given that at any given moment an ordinary object coincides with a section of matter, that is, is something that sustains properties and is sustained in existence only by God. In this sense, it is important to notice that ascribing 'being a substance' to something has no implication as regards any specific persistence conditions - for instance, as regards the conditions 
under which something becomes, or ceases to be, say, a human body, or a chair (remember that such changes have no relation with the kind of dependence relevant for the definition of substance). When a particular chair, then, or a human body, is considered to be a substance, it is not a substance qua chair, or qua human body, but only in so far as, at every stage of its career, it is, or it is constituted by, something, a piece of matter, that fulfils the functional roles just described. ${ }^{18}$

${ }^{18}$ I would like to thank audiences in Buenos Aires, Mar del Plata, Santiago de Chile and Temuco for questions and comments, in particular José Tomás Alvarado, Paula Castelli, Robert García, John Heil, Samuel Herrera, Felipe Johnson, Santiago Orrego and Jeff Snapper. Special thanks go to Mario Caimi and Gonzalo Rodriguez-Pereyra, who provided written comments on an earlier version of this paper. 


\section{REFERENCES}

\section{Primary sources:}

AT: Descartes, R. i996, Oeuvres de Descartes, Adam, Ch. and Tannery, P. (eds.), Paris: Vrin.

CSMK: Descartes, R. I984-I99I, The Philosophical Writings of Descartes, Cottingham, J., Stoothoff, R., Murdoch, D. and (for vol. 3) Kenny, A. (eds. and translators) Cambridge: CUP.

G: Spinoza, B. de 1925, Opera, Gebhardt, C. (ed.), Heidelberg: Winter, 1925.

\section{Modern works:}

Cartwright, H. i970, "Quantities", Journal of Philosophy, 79/1: 25-42. http://dx.doi.org/10.2307/2184067

Cottingham, J. i986, Descartes, Oxford: Blackwell.

Chappell, V. 20io, "Descartes on Substance", in A Companion to Descartes, Broughton, J. and Carriero, J. (eds.), Oxford: Blackwell.

Gueroult, M. 1953, Descartes selon l'ordre des raisons, Paris: Aubier.

Kemp Smith, N. 1953, New Studies in the Philosophy of Descartes. Descartes as Pioneer, London: Macmillan.

Markie, P. I994, "Descartes's Concepts of Substance", in Reason, Will and Sensation. Studies in Descartes's Metaphysics, Cottingham, J. (ed.), Oxford: OUP, 63-87.

Rodriguez-Pereyra, G. 2008, “Descartes's Substance Dualism and His Independence Conception of Substance", Journal of the History of Philosophy, 46/1: 69-90.

http://dx.doi.org/10.1353/hph.2008.1827

Rosenkranz, G. and Hoffman, J. i 99i, "The Independence Criterion of Substance", Philosophy and Phenomenological Research, 51/4: 835-53. http://dx.doi.org/10.2307/2108184

Rozemond, M. 20 i I, "Real Distinction, Separability, and Corporeal Substance in Descartes", Midwest Studies in Philosophy, 35: 240-58. http://dx.doi.org/10.1111/j.1475-4975.2011.00228.x

Secada, J. 2006, "The Doctrine of Substance", in The Blackwell Guide to Descartes" Meditations, Gaukroger, S. (ed.), Oxford: Blackwell. http://dx.doi.org/10.1002/9780470776476.ch5

SLowıK, E. 200I, "Descartes and Individual Corporeal Substance”, British Journal for the History of Philosophy, 9/1: 1-15. http://dx.doi.org/10.1080/09608780010012666 
SowaAl, A. 2004, "Cartesian Bodies", Canadian Journal of Philosophy, 34/2: 217-40.

Stuart, M. 1999, "Descartes's Extended Substances", in New Essays on the Rationalists, Gennaro, R. and Huenemann, Ch. (eds.), New York: OUP.

Williams, B. 1978, Descartes: The Project of Pure Enquiry, Hassocks: The Harvester Press.

Woolnouse, R. S. 1990, "Spinoza and Descartes and the Existence of Extended Substance", in Central Themes in Early Modern Philosophy, Cover, J. A. and Kulstad, M. (eds), Indianapolis: Hackett.

Woolhouse, R. S. 1993, Descartes, Spinoza, Leibniz. The concept of substance in seventeenth-century metaphysics, London \& New York: Routledge. 